\title{
A family with A20 haploinsufficiency presenting with novel clinical manifestations and
}

challenges for treatment

Timo Hautala ${ }^{1,15}$, Paula Vähäsalo ${ }^{2}$, Outi Kuismin ${ }^{3}$, Salla Keskitalo ${ }^{4}$, Kristiina Rajamäki ${ }^{5}$, Antti Väänänen ${ }^{6}$, Marja Simojoki ${ }^{7}$, Marjaana Säily ${ }^{1}$, Ilpo Pelkonen ${ }^{8}$, Heikki Tokola ${ }^{9}$, Markus Mäkinen ${ }^{9}$, Riitta Kaarteenaho ${ }^{10}$, Airi Jartti ${ }^{11}$, Nina Hautala ${ }^{12}$, Saara Kantola ${ }^{13}$ Päivi Jackson ${ }^{14}$, Virpi Glumoff ${ }^{15}$, Janna Saarela $^{16}$, Markku Varjosalo ${ }^{4,17}$, Kari K Eklund ${ }^{18}$, Mikko RJ Seppänen ${ }^{5,19}$

${ }^{1}$ Department of Internal Medicine, Oulu University Hospital, Oulu, Finland.

${ }^{2}$ Department of Pediatrics, PEDEGO Research Unit, Medical Research Center, Oulu University Hospital and University of Oulu, Oulu, Finland.

${ }^{3}$ Department of Clinical Genetics, PEDEGO Research Unit, Medical Research Center, Oulu University Hospital and University of Oulu, Oulu, Finland.

${ }^{4}$ Institute of Biotechnology, Helsinki Institute of Life Science (HiLIFE), University of Helsinki, Helsinki, Finland.

${ }^{5}$ Clinicum, Faculty of Medicine, University of Helsinki, Helsinki, Finland

${ }^{6}$ Department of Infection Control, Lapland Central Hospital, Rovaniemi, Finland.

${ }^{7}$ Department of Obstetrics and Gynecology, Oulu University Hospital, Oulu, Finland

${ }^{8}$ Hematology Laboratory, Nordlab Oulu, Oulu University Hospital, Oulu, Finland

${ }^{9}$ Department of Pathology, Cancer Research and Translational Medicine Research Unit, University of Oulu and Oulu University Hospital, Oulu, Finland.

${ }^{10}$ Respiratory Medicine, Research Unit of Internal Medicine, University of Oulu and Medical Research Center Oulu, Oulu University Hospital, Oulu, Finland.

${ }^{11}$ Department of Radiology, Oulu University Hospital, Oulu, Finland

${ }^{12}$ Department of Ophthalmology, PEDEGO Research Unit, Medical Research Center, Oulu University Hospital and University of Oulu, Oulu, Finland.

${ }^{13}$ Department of Dentistry, Oulu University Hospital, Oulu, Finland

${ }^{14}$ Department of Dermatology, Oulu University Hospital, Oulu, Finland

${ }^{15}$ Research Unit of Biomedicine, University of Oulu, Oulu, Finland.

${ }^{16}$ Institute for Molecular Medicine Finland, Helsinki Institute of Life Science (HiLIFE), University of Helsinki, Helsinki, Finland.

${ }^{17}$ Proteomics Unit, Institute of Biotechnology, University of Helsinki, Helsinki, Finland.

${ }^{18}$ Department of Rheumatology, Inflammation Center, University of Helsinki and Helsinki University Hospital. Research Institute, Invalid Foundation. Orton Orthopedic Hospital, Helsinki, Finland. 
${ }^{19}$ Rare Diseases Center and Pediatric Research Center, Children and Adolescents and Adult Immunodeficiency Unit, Inflammation Center, University of Helsinki and Helsinki University Hospital, Helsinki, Finland.

Keywords: immunodeficiency, autoimmunity, autoinflammation, lung disease, anemia, anakinra, mycophenolate

Running title: Multiple immunological defects due to HA20

\section{Corresponding author:}

Timo Hautala, MD, PhD

Research Unit of Biomedicine

University of Oulu

P.O. Box 20

FIN-90029 OYS, Finland

Phone: +358 407096859

E-mail: timo.hautala@fimnet.fi 


\section{ABSTRACT}

Background. Tumor necrosis factor alpha-induced protein 3 gene (TNFAIP3, also called A20) haploinsufficiency (HA20) leads to autoinflammation and autoimmunity. We have recently shown that a p.(Lys91*) mutation in A20 disrupts NF- $\kappa \mathrm{B}$ signaling, impairs protein-protein interactions of A20, and leads to inflammasome activation.

Methods. We now describe the clinical presentations and drug responses in a family with HA20 p.(Lys91*) mutation, consistent with our previously reported diverse immunological and functional findings.

Results. We report for the first time that inflammasome-mediated autoinflammatory lung reaction caused by HA20 can be treated with IL-1 antagonist anakinra. We also describe severe anemia related to HA20 successfully treated with mycophenolate. In addition, HA20 p.(Lys91*) was found to associate with autoimmune thyroid disease, juvenile idiopathic arthritis, psoriasis, liver disease and immunodeficiency presenting with specific antibody deficiency and genital papillomatosis.

Conclusions. We conclude that HA20 may lead to combination of inflammation, immunodeficiency and autoimmunity. The condition may present with variable and unpredictable symptoms with atypical treatment responses.

\section{INTRODUCTION}

Haploinsufficiency of A20 (HA20) is an autoinflammatory and autoimmune condition caused by loss of function mutations in tumor necrosis factor alpha-induced protein 3 gene (TNFAIP3, also called A20) $[1,2,3,4,5,6]$. Most typically, HA20 patients are reported to suffer from juvenile arthritis or Behçet's like disease. In addition, gastrointestinal complaints, skin involvement, recurrent fever, 
vasculitis and uveitis, for example, may associate with HA20. In addition to these clinical consequences, A20 has been shown to regulate T cell maturation [7] and to participate for example in development of steatohepatitis in experimental models [8].

We recently described molecular mechanisms of HA20 caused by a truncating mutation p.(Lys91*). Various biological consequences included reduced NF- $\kappa \mathrm{B}$ signaling, severely impaired proteinprotein interactions of A20, and caspase-8-dependent inflammasome activation [9]. The patients had increased secretion of interleukin (IL)-1beta, IL-18 and tumor necrosis factor alpha (TNF- $\alpha$ ) after stimulation of peripheral blood immune cells. We now report in detail the clinical presentations in the family and the challenges faced in the treatment of these patients. Clinical details and explicit experience on drug responses in HA20 patients are only briefly described in the literature. We now describe, for example, successful anakinra effect on lung autoinflammation and a mycophenolate mofetil response on HA20 related anemia for the first time.

\section{PATIENTS AND METHODS}

A family with HA20 with (Ensembl ENSG00000118503:ENST00000433680:exon2:c.A271T: p.(Lys91*) was analyzed for their immunological properties, clinical symptoms and responses to disease-modifying antirheumatic drug (DMARD) treatments. The mutation was first found in patient II:1 as described previously [9]. Disease course, treatment regimens, and disease- and treatmentrelated complications were recorded. Patient consent, or a consent from a parent was obtained by the responsible physician.

Immunological properties including lymphocyte subpopulations and their maturation were analyzed

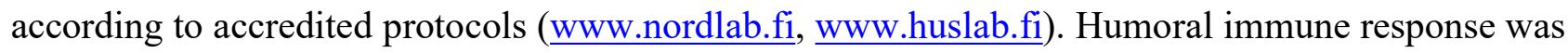
tested with pneumococcus polysaccharide (Pneumovax $\left.{ }^{\circledR}\right)$ vaccination. T helper 17 (Th17), 
107 interleukin 17 (IL-17), and signal transducer and activator of transcription 3 (STAT3) were analyzed 108 as described [10] .

\section{RESULTS}

112 A family with A20 p.(Lys91*) mutation (Figure 1) was analyzed for their clinical immunology, 113 symptoms and responses to disease-modifying antirheumatic drug (DMARD) treatments. Clinical 114 histories are explained in the Supplement. The symptoms and the responses to various treatments are 115 summarized in Table 1.

\section{Immunological parameters}

118 Blood lymphocyte and B cell counts were within normal range in all family members. Patients II:1 119 and II:4 had an elevated percentage of activated CD2 $1{ }^{\text {low }} \mathrm{CD} 38^{\text {low }}$ B-cells $13.7-15.7 \%$ (reference 0.8 $120-7.7 \%$ ) and low percentage of switched memory B cells $3.2-6.1 \%$ (reference $6.5-29.2 \%$ ). Despite 121 normal plasma IgG of $10.8-12.9 \mathrm{~g} / \mathrm{L}$ (reference 6.7 - $15.0 \mathrm{~g} / \mathrm{L}$ ) levels, they (patient II:1, response 122 to $2 / 10$ serotypes) and (patient II:4, response to $1 / 10$ serotypes) displayed specific antibody deficiency 123 with marginal response to pneumococcal polysaccharide vaccine (Pneumovax ${ }^{\circledR}$ ). Immunological 124 parameters including a slightly low IgG2 serum concentration in patient II: 1 are summarized in 125 Supplemental Table 1.

127 Although blood $\mathrm{T}$ cell counts were normal, numbers of $\mathrm{CD}^{+} \mathrm{CD}^{+} \mathrm{T}$ cells $\left(314 \times 10^{6} / \mathrm{L}\right.$; reference $128404-1612)$ and natural killer cells $\left(30-68 \times 10^{6} / \mathrm{L}\right.$, reference $\left.84-724\right)$ were low in patient II:1. 129 Interleukin-17 expression on anti-CD3/CD28-stimulated $\mathrm{CD}^{+} \mathrm{CD}^{+} \mathrm{T}$ cells was normal (patient $1300.63 \%$, control $0.86 \%$ ) while the relative numbers of T helper 17 (Th17) $\mathrm{CD}^{+} \mathrm{CD}^{4} 5 \mathrm{RA}^{-} \mathrm{CXCR} 3^{-}$ 
$131 \mathrm{CCR}^{+}$memory cells were somewhat low $(11.4 \%$; reference $19-34 \%)$. Signal transducer and

132 activator of transcription 3 (STAT3) phosphorylation was normal [11].

\section{Thyroid disease}

135 All affected family members suffered from early-onset autoimmune thyroid disease (AITD) 136 associated with growth delay and positive anti-thyroid peroxidase antibodies. Growth delays were 137 resolved in early childhood after introduction of thyroid replacement therapy.

\section{Pulmonary inflammation}

140 At age of 28 years, patient II:1 developed prolonged fever and respiratory distress. No evidence of 141 infection nor responses to broad-spectrum antibiotics were seen. High-resolution computed 142 tomography of her chest was consistent with follicular bronchiolitis or lymphatic hyperplasia (Figure $1432 \mathrm{~A}-\mathrm{B})$. Anakinra treatment (100 $\mathrm{mg} \mathrm{x} \mathrm{1)} \mathrm{led} \mathrm{to} \mathrm{a} \mathrm{rapid} \mathrm{and} \mathrm{complete} \mathrm{resolution} \mathrm{of} \mathrm{the} \mathrm{pulmonary}$ 144 nodules and respiratory symptoms (Figure 2 C-D).

\section{Anemia}

147 At age 30, patient II:1 developed acute anemia (hemoglobin $72 \mathrm{~g} / 1$, mean cellular volume (MCV) 85 fl) followed by peripheral blood reticulocytosis and macrocytosis (MCV $100-102 \mathrm{fl}$ ). The parameters associated with anemia are described in detail in Supplement. Responses to blood transfusions were at best modest (Supplement Table), there was no active bleeding, and the condition

151 was inconsistent with known inflammatory or other causes for anemia. Serum hepsidin levels were 152 low, plasma erythropoietin was stimulated, and she exhibited an active erythropoiesis in her bone 153 marrow. Markers for hemolysis (Coombs test, serum haptoglobin, plasma hemoglobin, urine 154 hemosiderin) were negative and criteria for hemophagocytic lymphohistiocytosis were not met. There 
$\alpha$ (etanercept) or JAK inhibition (tofacitinib) [12]. Although her anemia was controlled with $\geq 20 \mathrm{mg}$ of daily oral prednisolone, she was unable to tolerate prolonged treatment. After numerous treatment attempts, mycophenolate mofetil (500 mg two times per day) seemed to stabilize her blood hemoglobin concentration (Supplement Table).

\section{Liver involvement}

Patient I: 1 had developed liver disease of uncertain etiology. She had been advised to avoid alcohol and medications with potential of liver toxicity. At age 46 , she had experienced progression of the liver disease and she had been diagnosed with cirrhosis of the liver, eventually causing her death. Patient II:1 underwent abdominal magnetic resonance imaging (MRI) in which iron accumulation into liver was suggested. Liver biopsy confirmed hepatosteatosis and an iron load in Kupffer cells and sinusoidal macrophages (Figure 2 E-F). Mild elevations in plasma alanine aminotransferase (36 -68 , reference $<35$ units/liter $)$ and plasma bilirubin concentrations $(29-44$, reference $<25 \mu \mathrm{mol} / \mathrm{l})$ were observed. No sign of liver dysfunction or fibrosis was found.

\section{Oral and genital ulceration}

The patient II:1 had suffered from aphthous stomatitis and genital ulcers for several years. Oral aphthous disease responded very favorably to TNF- $\alpha$ inhibitor etanercept although this treatment was ineffective against anemia. She developed chronic and resistant genital papillomatosis during follow up, suggesting mild combined immunodeficiency. Immune response modifier imiquimod or CO2laser treatments had no effect. Papillomatosis paradoxically improved strikingly during the mycophenolate treatment against anemia.

\section{Arthritis}


180 Patient III:1, with early-onset polyarticular juvenile arthritis, failed to tolerate or respond to various

181 medications summarized in the Supplement and Table 1. She also generated antibodies against 182 infliximab and golimumab. Finally, good response and tolerability were achieved with a combination 183 of azathioprine and high golimumab dose to block drug antibodies.

DISCUSSION

HA20 p.(Lys91*) disrupts regulation of multiple immunological pathways involving inflammation and immunity. Patient's lung condition was most likely caused by inflammasome dysregulation. Lung disease responsive to IL-1 antagonist anakinra and aphthous stomatitis alleviated with TNF- $\alpha$ inhibitor etanercept together with our previously published results conform to abnormal NLRP3

191 inflammasome activity [9]. To our knowledge, this is the first description of monogenic inborn error of immunity, in which anakinra has reversed severe pulmonary autoinflammation.

Atypical and treatment resistant anemia led us to consider a possibility of $\mathrm{T}$ cell-mediated mechanisms and to test empiric and generally well-tolerated mycophenolate mofetil treatment. The positive mycophenolate effect on anemia suggests a potential role for cytotoxic $\mathrm{CD} 3^{+} \mathrm{CD} 8^{+} \mathrm{T}$ cells, while failure to respond to IL- 1 and TNF- $\alpha$ inhibition suggests mechanisms other than increased

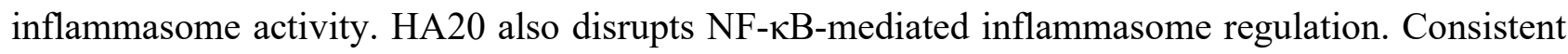
with more widely dysregulated NF-אB due to p.(Lys91*), signs of aberrant B-cell development with low switched memory B cells, elevated "immune-exhausted" $\mathrm{C} 21^{\text {low }} \mathrm{CD} 38^{\text {low }} \mathrm{B}$ cells, specific 201 antibody deficiency and production of autoantibodies were noted. These and the severe genital papillomatosis suggest that HA20 may clinically cause mild combined immunodeficiency. The exact etiopathogenesis and potential responses to mycophenolate need to be studied in larger cohorts of HA20. 
206 Our study was limited to a single rare A20 variant only and our experience should thus be interpreted 207 cautiously when planning treatment of HA20 patients with various mutations. However, coexistence 208 of multiple autoimmune conditions and infection susceptibility presenting in several organs is 209 unusual. Familial early onset autoimmune thyroid disease with growth delay, for example, should 210 lead to consideration of HA20. Lung inflammation, anemia and liver disease are also examples of 211 diversity of the A20 biological functions and the role in development of autoimmunity; it is possible 212 that HA20 disrupts signaling pathways even beyond the regulation of immunity. The widely 213 heterogenous phenotypes, diversity of immunological findings and unpredictable responses to 214 DMARD or bDMARD therapies signify an important clinical role for A20. We recommend that the 215 exact etiopathogenesis of HA20 caused by different TNFAIP3 mutations should be further explored. 


\section{Legend for Table 1.}

217 Summary of symptoms and age of onset of the symptoms associated with HA20 in the affected 218 family. Response to each treatment is summarized.

\section{Legend for Figure 1.}

221 A pedigree of the family with TNFAIP3 p.(Lys91*) (K91X) in three generations. Solid symbols show 222 the affected family members (positive for heterozygous for K91X mutation, +/-) described in detail 223 in the Supplement. White symbols show unaffected family members negative for K91X mutation ($224 /-)$

\section{Legend for Figure 2.}

227 Axial and coronal computed tomography (CT) scans of the chest demonstrates bilateral patchy 228 peribronchial nodular pulmonary opacities before treatment (A, B). After 1.5 months of anakinra (100 $229 \mathrm{mg} \mathrm{x} 1 \mathrm{sc}$ ) treatment all the pulmonary lesions have disappeared completely (C, D). Histology of liver 230 shows moderate hepatosteatosis (E, Hematoxylin-Eosin) and iron accumulation in the Kupffer cells 231 and sinusoidal macrophages (F, Prussian Blue).

Declarations

234 Ethics approval: The study has been approved by ethical committee of Oulu University Hospital. 235 Informed consent was obtained. The study was conducted according to the guidelines of Declaration 236 of Helsinki.

237 Consent for participation: Consent for participation was obtained.

238 Consent for publication: Consent for publication was obtained.

239 Availability of data and material: Not applicable

240 Competing interests: No competing interests. 
241 Funding: Oulu and Helsinki University Hospital Research Funds.

242 Authors' contributions: TH, PV, AV, MS, MS, RK, NH, SK, PJ were responsible for treatment and

243 follow up of treatment outcome. SK, KR, IP, VG, MV, KKE completed immunological analysis. HK,

244 MM analyzed tissue histology. AJ completed radiological analysis. OK, JS completed genetic 245 analysis. TH, KKE, MRJS were responsible for study design. All authors read and approved the final 246 manuscript.

247 Acknowledgements: Not applicable

\section{References}

1. Zhou Q, Wang H, Schwartz DM, Stoffels M, Park YH, Zhang Yet al. Loss-of-function mutations in TNFAIP3 leading to A20 haploinsufficiency cause an early-onset autoinflammatory disease. Nat.Genet. 2016;48:67-73.

2. Aksentijevich I, Zhou Q. NF-kappaB Pathway in Autoinflammatory Diseases: Dysregulation of Protein Modifications by Ubiquitin Defines a New Category of Autoinflammatory Diseases. Front Immunol. 2017;8:399

3. Aksentijevich I, McDermott MF. Lessons from characterization and treatment of the autoinflammatory syndromes. Curr.Opin.Rheumatol. 2017;29:187-194.

4. Das T, Chen Z, Hendriks RW, Kool M. A20/Tumor Necrosis Factor alpha-Induced Protein 3 in Immune Cells Controls Development of Autoinflammation and Autoimmunity: Lessons from Mouse Models. Front Immunol. 2018;9:104

5. Berteau F, Rouviere B, Delluc A, Nau A, Le BR, Sarrabay Get al. Autosomic dominant familial Behcet disease and haploinsufficiency A20: A review of the literature. Autoimmun.Rev. 2018;17:809-815.

6. Aeschlimann FA, Batu ED, Canna SW, Go E, Gul A, Hoffmann P et al. A20 haploinsufficiency (HA20): clinical phenotypes and disease course of patients with a newly recognised NF-kB-mediated autoinflammatory disease. Ann.Rheum.Dis. 2018;77:728-735.

7. Fischer JC, Otten V, Kober M, Drees C, Rosenbaum M, Schmick1 M et al. A20 Restrains Thymic Regulatory T Cell Development. J.Immunol. 2017;199:2356-2365.

8. Zhang P, Wang PX, Zhao LP, Zhang X, Ji YX, Zhang XJ_et al. The deubiquitinating enzyme TNFAIP3 mediates inactivation of hepatic ASK1 and ameliorates nonalcoholic steatohepatitis. Nat.Med. 2018;24:84-94. 
9. Rajamäki K, Keskitalo S, Seppänen M, Kuismin O, Vähäsalo P, Trotta L et al. Haploinsufficiency of A20 impairs protein-protein interactome and leads into caspase-8dependent enhancement of NLRP3 inflammasome activation. RMD.Open. 2018;4:e000740

10. Haapaniemi EM, Kaustio M, Rajala HL, van Adrichem AJ, Kainulainen L, Glumoff V et al. Autoimmunity, hypogammaglobulinemia, lymphoproliferation, and mycobacterial disease in patients with activating mutations in STAT3. Blood 2015;125:639-648.

11. Iwanaga N, Kolls JK. Updates on T helper type 17 immunity in respiratory disease. Immunology 2019;156:3-8.

12. Mulhern CM, Hong Y, Omoyinmi E, Jacques TS, D'Arco F, Hemingway C et al. Janus kinase $1 / 2$ inhibition for the treatment of autoinflammation associated with heterozygous TNFAIP3 mutation. J.Allergy Clin.Immunol. 2019;144:863-866. 


\begin{tabular}{|c|c|c|}
\hline & Symptoms, age of diagnosis & Treatment, response \\
\hline \multirow[t]{4}{*}{ Patient 1} & AITD, age not known & thyroid replacement therapy, responded \\
\hline & Hepatitis, 43 & no documented treatment \\
\hline & Anemia, 43 & no documented treatment \\
\hline & Liver failure, 46 & death \\
\hline \multirow[t]{9}{*}{ Patient 2} & AITD, growth delay, 4 & thyroid replacement therapy, responded \\
\hline & Atrophic gastritis, 21 & B12 substitution, increased serum B12 levels \\
\hline & Psoriasis, 23 & topical calcipotriol, corticosteroids and econazole, parti \\
\hline & Aphtous stomatitis & $\begin{array}{l}\text { anakinra, no response } \\
\text { canakinumab, no response } \\
\text { etarnecept, complete response }\end{array}$ \\
\hline & Genital papillomatosis, 25 & $\begin{array}{l}\text { imiquimod, carbon dioxide }(\mathrm{CO} 2) \text { laser therapy, no res } \\
\text { mycophenolate, complete response }\end{array}$ \\
\hline & $\begin{array}{l}\text { Episodes of oral and genital HSV, } \\
\text { based on clinical presentation }\end{array}$ & acyclovir, partial response \\
\hline & Pulmonary inflammation & $\begin{array}{l}\text { broad spectrum antibiotics, no response } \\
\text { prednisolone, no response } \\
\text { anakinra, good response }\end{array}$ \\
\hline & Anaphylactoid reactions, $28-31$ & prednisolone, good response \\
\hline & Anemia, 30 & $\begin{array}{l}\text { prednisolone, good response, poor tolerance } \\
\text { canakinumab, no response } \\
\text { iv IG, no response } \\
\text { etanercept, no response } \\
\text { tofacitinib, poor tolerance, cytopenia }\end{array}$ \\
\hline
\end{tabular}




\begin{tabular}{|c|c|c|}
\hline & & mycophenolate, good response \\
\hline & $\begin{array}{l}\text { Hepatosteatosis } \\
\text { Liver iron load, } 30\end{array}$ & no specific treatment \\
\hline \multirow[t]{2}{*}{ Patient 3} & AITD, growth delay & thyroid replacement therapy, good response \\
\hline & Anemia & no specific treatment \\
\hline \multirow[t]{3}{*}{ Patient 4} & Cow's milk allergy & \\
\hline & AITD, 1.6 & thyroid replacement therapy, good response \\
\hline & Juvenile idiopathic arthritis, 4.6 & $\begin{array}{l}\text { prednisolone and methotrexate, poor tolerance } \\
\text { etanercept, poor response } \\
\text { adalimumab and azathioprine, good response, poor tol } \\
\text { tocilizumab and iv methylprednisolone, poor response } \\
\text { adalimumab and methotrexate, partial response } \\
\text { infliximab and methotrexate, good response, poor metl } \\
\text { infliximab, insufficient response, infliximab antibodies } \\
\text { anakinra, poor tolerance, uncertain response } \\
\text { golimumab (recommended dose), leflunomide and } \\
\text { response, golimumab antibodies } \\
\text { golimumab (high dose) and azathioprine, good respons }\end{array}$ \\
\hline
\end{tabular}


I

II

III

324

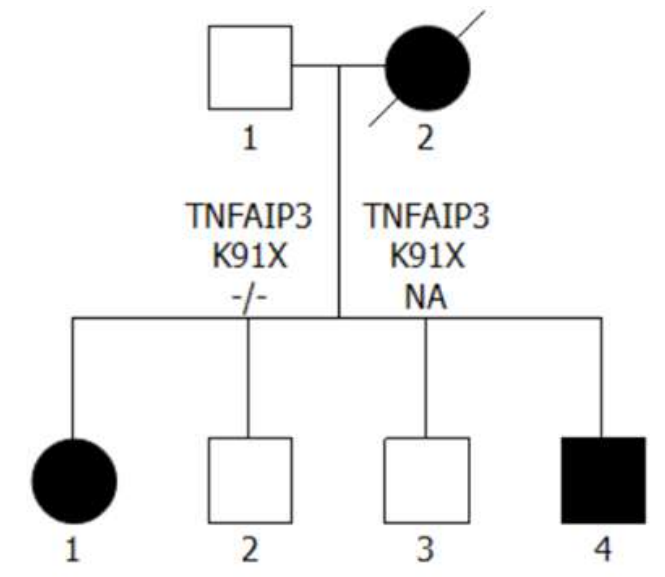

TNFAIP3 TNFAIP3 TNFAIP3 TNFAIP3

$\begin{array}{cccc}\text { K91X } & \text { K91X } & \text { K91X } & \text { K91X } \\ -/+ & \text { NA } & -/- & -/+\end{array}$

325

326

TNFAIP3

K91X

$-1+$ 


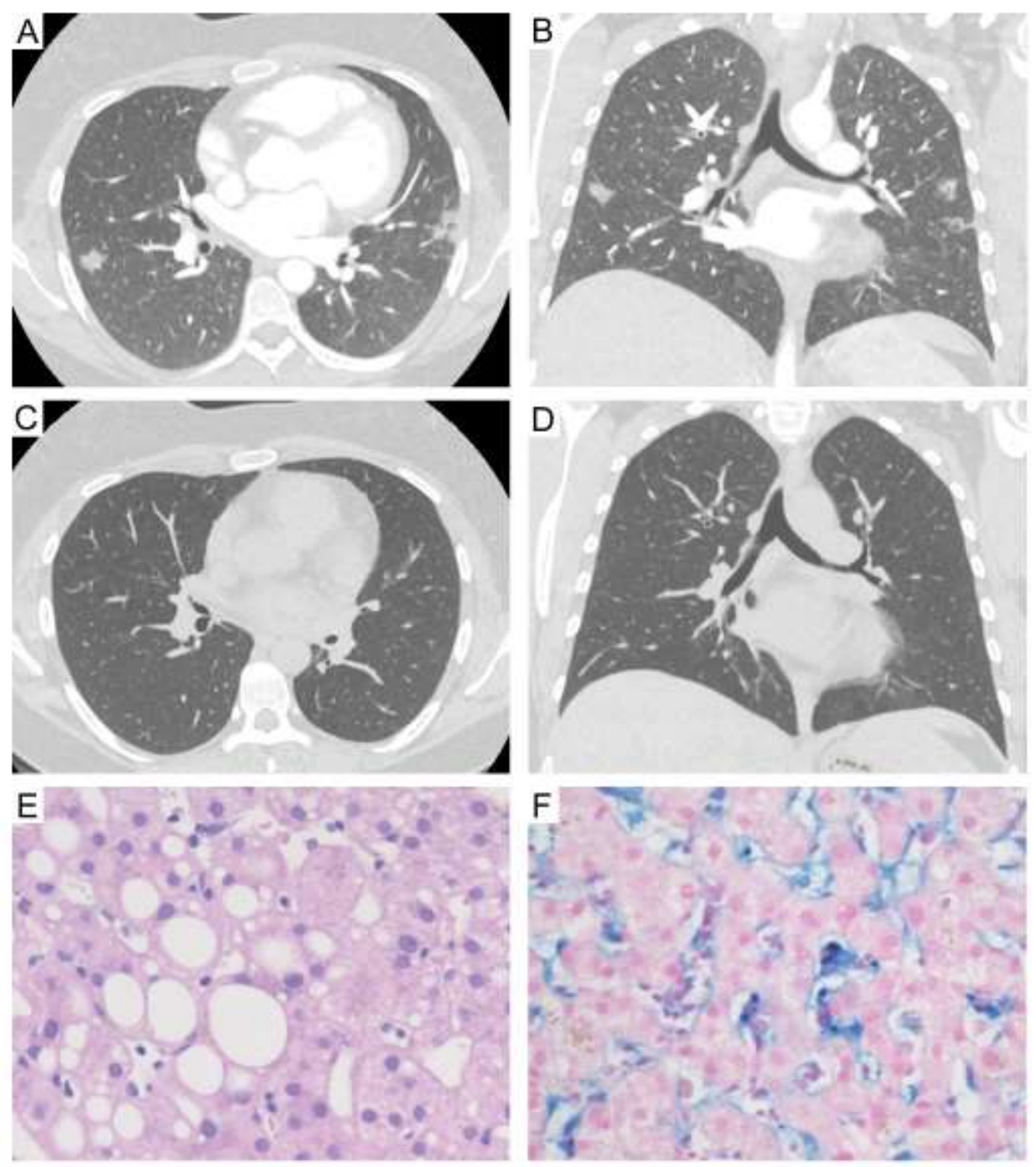

Hautala et al. Figure 2

Colour Image 


\section{Supplemental document}

335 Patient I:2. Case description is based on hospital records. Since age 7, she (mother of II:1 and II:4) 336 suffered from hypothyroidism treated with thyroid hormone replacement therapy. Between ages 30 337 and 40, she experienced recurrent bone fractures due to osteoporosis, serum vitamin-D-25-OH 338 concentration $(<10 \mathrm{nmol} / \mathrm{L}$, normal range $75-250 \mathrm{nmol} / \mathrm{L})$ was low. Biopsies taken during 339 gastroscopy due to low blood hemoglobin levels found atrophic gastritis. Age 43, she experienced a 340 spell of unconsciousness. Brain computed tomography scan (CT) was unremarkable and her 341 abdominal ultrasound was consistent with enlarged liver. Her liver enzymes were elevated: alanine 342 transaminase $95 \mathrm{U} / \mathrm{L}$ (normal range 10 - 45), aspartate transaminase $284 \mathrm{U} / \mathrm{L}$ (normal range 15 - 35) 343 and alkaline phosphatase $464 \mathrm{U} / \mathrm{L}$ (normal range $35-105$ ). She was advised to avoid alcohol and 344 medications with of liver toxicity. Age 46, she died of severe liver cirrhosis accompanied by weight 345 loss and jaundice.

346 Patient II:1. Our index, a 30-year-old daughter of Patient I:2, had episodes of purulent otitis media 347 and infectious pharyngitis in her childhood. At age 4, autoimmune hypothyroidism was noticed due 348 to growth delay. Soon after an uncomplicated pregnancy (patient III:1) at age 21, she was found to 349 suffer from atrophic gastritis and low vitamin B12 levels. At age 23, she developed skin psoriasis and 350 psoriatic arthritis. At age 25, she developed treatment resistant genital papillomatosis and she suffered 351 her first pneumonia. At age 28, she experienced an episode of prolonged oral and genital herpes, 352 while also affected by genital papillomatosis. The diagnoses were based on clinical judgement.

353 At age 28 she was hospitalized due to fever and respiratory distress. Bacterial, mycobacterial, viral 354 and fungal tests remained negative; antimicrobial treatments were ineffective, but she developed 355 clostridial hemorrhagic colitis. For months after the acute phase, she suffered from severely 356 incapacitating respiratory distress. Her chest high resolution computed tomography (HRCT) 357 remained abnormal; findings suggested follicular bronchiolitis or bronchial lymphatic hyperplasia. 
358 The combination of various complicated infectious, inflammatory and autoimmune diseases, and 359 abnormal family history lead to basic immunologic testing with modest abnormalities (Supplement

360 Table 1). Next, she and her family underwent whole exome sequencing (Rajamäki et al). A novel 361 nonsense mutation in the exon 2 of TNFAIP3, c.A271T;p.(Lys91*) 362 (ENSG00000118503:ENST00000433680) and functional testing confirmed haploinsufficiency of 363 A20 (HA20) (Rajamäki et al). Consequently, autoinflammatory lung reaction was suspected. 364 Administration of interleukin 1 antagonist anakinra led to rapid and complete resolution of her lung 365 symptoms and radiologic abnormalities in chest HRCT (Figure 1, main document).

366 Supplement Table 1. Immunologic testing of patients.

\begin{tabular}{|c|c|c|c|}
\hline & Patient II:1 & Patient II:4 & Reference \\
\hline B-leukocyte count & $5.5 \times 10^{9} / \mathrm{L}$ & $6.5 \times 10^{9} / \mathrm{L}$ & $3.4-8.2 \times 10^{9} / \mathrm{L}$ \\
\hline B-lymphocyte count & $1.7 \times 10^{9} / \mathrm{L}$ & $1.8 \times 10^{9} / \mathrm{L}$ & $1.2-3.5 \times 10^{9} / \mathrm{L}$ \\
\hline CD19 & $0.43 \times 10^{9} / \mathrm{L}$ & $0.35 \times 10^{9} / \mathrm{L}$ & $0.080-0.616 \times 10^{9} / \mathrm{L}$ \\
\hline switched memory B cells & $3.2 \% \downarrow$ & $6.1 \% \downarrow$ & $6.5-29.2 \%$ \\
\hline activated B cells (CD21 $\left.{ }^{\text {low }} \mathrm{CD} 38^{\text {low }}\right)$ & $13.7 \% \uparrow$ & $15.7 \% \uparrow$ & $0.8-7.7 \%$ \\
\hline CD3 & $1.30 \times 10^{9} / \mathrm{L}$ & $1.34 \times 10^{9} / \mathrm{L}$ & $0.742-2.750 \times 10^{9} / \mathrm{L}$ \\
\hline CD4 & $0.76 \times 10^{9} / \mathrm{L}$ & $0.76 \times 10^{9} / \mathrm{L}$ & $0.404-1.612 \times 10^{9} / \mathrm{L}$ \\
\hline CD8 & $0.50 \times 10^{9} / \mathrm{L}$ & $0.62 \times 10^{9} / \mathrm{L}$ & $0.220-1.129 \times 10^{9} / \mathrm{L}$ \\
\hline $\begin{array}{l}\text { Recent thymic emigrants } \\
\left(\mathrm{CD} 45^{+} \mathrm{CD} 62 \mathrm{~L}^{+} \mathrm{CD} 31^{+}\right)\end{array}$ & $7.8 \% \downarrow$ & $27.5 \%$ & $14.4-38.3 \%$ \\
\hline $\mathrm{NK}$ & $\begin{array}{l}0.053 \times 10^{9} / \mathrm{L} \\
\downarrow\end{array}$ & $0.13 \times 10^{9} / \mathrm{L}$ & $0.084-0.724 \times 10^{9} / \mathrm{L}$ \\
\hline S-IgA & $1.24 \mathrm{~g} / \mathrm{L}$ & $2.19 \mathrm{~g} / \mathrm{L}$ & $0.52-4.02 \mathrm{~g} / \mathrm{L}$ \\
\hline S-IgE & $25 \mathrm{U} / \mathrm{L}$ & $2 \mathrm{U} / \mathrm{L}$ & $<110 \mathrm{U} / \mathrm{L}$ \\
\hline S-IgM & $2.05 \mathrm{~g} / \mathrm{L}$ & $1.00 \mathrm{~g} / \mathrm{L}$ & $0.47-2.84 \mathrm{~g} / \mathrm{L}$ \\
\hline S-IgG & $12.8 \mathrm{~g} / \mathrm{L}$ & $12.9 \mathrm{~g} / \mathrm{L}$ & $6.77-15.0 \mathrm{~g} / \mathrm{L}$ \\
\hline S-IgG1 & $10.9 \mathrm{~g} / \mathrm{L}$ & - & $4.05-10.11 \mathrm{~g} / \mathrm{L}$ \\
\hline S-IgG2 & $1.68 \mathrm{~g} / \mathrm{L}$ & - & $1.89-7.86 \mathrm{~g} / \mathrm{L}$ \\
\hline S-IgG3 & $0.60 \mathrm{~g} / \mathrm{L}$ & - & $0.11-0.65 \mathrm{~g} / \mathrm{L}$ \\
\hline S-IgG4 & $0.013 \mathrm{~g} / \mathrm{L}$ & - & $0.03-2.01 \mathrm{~g} / \mathrm{L}$ \\
\hline $\begin{array}{l}\text { Anti-polysaccharide vaccine } \\
\text { responses to Pneumovax }{ }^{\circledR} \text {, of } 10 \\
\text { tested serotypes* }\end{array}$ & $2 / 10 \downarrow \downarrow$ & $1 / 10 \downarrow \downarrow$ & \\
\hline
\end{tabular}

367 Tested routinely in an accredited laboratory. * for the used multiplex method see Selenius et al. 
368 She developed treatment resistant anemia of unknown cause. The laboratory results, summarized in

369 Supplemental Table 2, were not consistent with a known cause (e.g. hemolysis, inflammatory 370 anemia). Though active reticulocyte production was seen in the bone marrow and the peripheral 371 blood, in extensive hospital investigations and observation there was no proof of hemoglobin loss 372 through feces, urine, exsanguination or intravascularly during her constantly worsening anemia.

373 Finally, due to HA20, no evidence of B cell-mediated or other known causes of anemia and a theoretic 374 possibility of $\mathrm{T}$ cell-mediated anemia, oral mycophenolate mofetil $500 \mathrm{mg}$ x 2 - a generally well375 tolerated drug suppressing T cell-mediated immunity - was empirically tested (see the main article 376 and Supplemental Table 3).

377 Supplemental Table 2. Anemia-related testing in patient II:1.

\begin{tabular}{|l|l|l|}
\hline & Patient II:1 & reference \\
\hline B-Hemoglobin & $72 \mathrm{~g} / \mathrm{L}$ & $117-155 \mathrm{~g} / \mathrm{L}$ \\
\hline P-Hemoglobin & $20 \mathrm{mg} / \mathrm{L}$ & $<50 \mathrm{mg} / \mathrm{L}$ \\
\hline E-Mean cellular volume & $85 \mathrm{fl}$ & $82-98 \mathrm{fl}$ \\
\hline B-Reticulocytes & $218 \times 10^{9} / \mathrm{L} / 7.0 \%$ & $26-95 \times 10^{9} / \mathrm{L} / 0.6-2.0 \%$ \\
\hline P-Lactate dehydrogenase & $175 \mathrm{U} / \mathrm{L}$ & $105-205 \mathrm{U} / \mathrm{L}$ \\
\hline P-Interleukin-2-receptor & $276 \mathrm{U} / \mathrm{L}$ & $160-620 \mathrm{U} 7 \mathrm{~L}$ \\
\hline P-interleukin-6 & $5.0 \mathrm{ng} / \mathrm{L}$ & $<7 \mathrm{ng} / \mathrm{L}$ \\
\hline Coombs & negative & negative \\
\hline S-Transferrin receptor & $1.9 \mathrm{mg} / \mathrm{L}$ & $0.8-1.8 \mathrm{mg} / \mathrm{L}$ \\
\hline S-Ferritin & $1055 \mu \mathrm{g} / \mathrm{L}$ & $5-90 \mu \mathrm{g} / \mathrm{L}$ \\
\hline S-transferrin & $2.6 \mathrm{~g} / \mathrm{L}$ & $1.8-3.2 \mathrm{~g} / \mathrm{L}$ \\
\hline P-triglycerides & $0.96 \mathrm{mmol} / \mathrm{L}$ & $<1.7 \mathrm{mmol} / \mathrm{L}$ \\
\hline S-cobalamin & $218 \mathrm{pmol} / \mathrm{L}$ & $180-700 \mathrm{pmol} / \mathrm{L}$ \\
\hline S-haptoglobin & $0.78 \mathrm{~g} / \mathrm{L}$ & $0.29-2.0 \mathrm{~g} / \mathrm{L}$ \\
\hline S-erythropoetin & $181 \mathrm{U} / \mathrm{L}$ & $4.3-29 \mathrm{U} / \mathrm{L}$ \\
\hline U-hemosiderin & negative & negative \\
\hline
\end{tabular}


382 Supplemetal Table 3. Response of patient II:1 to selected treatments of anemia.

383 The patient suffered from anemia of unknown cause as described in the main document. Panels A 384 and B show blood hemoglobin concentrations (g/Liter) $(\mathrm{A})$ blood reticulocyte counts $\left(\times 10^{9} / \mathrm{L}\right)(\mathrm{B})$ 385 during daily prednisolone $10 \mathrm{mg}$ of mycophenolate mofetil $500 \mathrm{mg}$ x 2 dose. A lasting positive effect 386 was observed, after the patient started receiving oral mycophenolate mofetil $500 \mathrm{mg}$ twice daily. 387 Weeks of treatment are shown in panels A and B. Panel C shows the effect of blood transfusions (red 388 arrows, a 14-day time-period) and panel D shows the effect of weekly etanercept injections (black 389 arrows, 1 month time-period) on blood hemoglobin concentration (g/Liter).
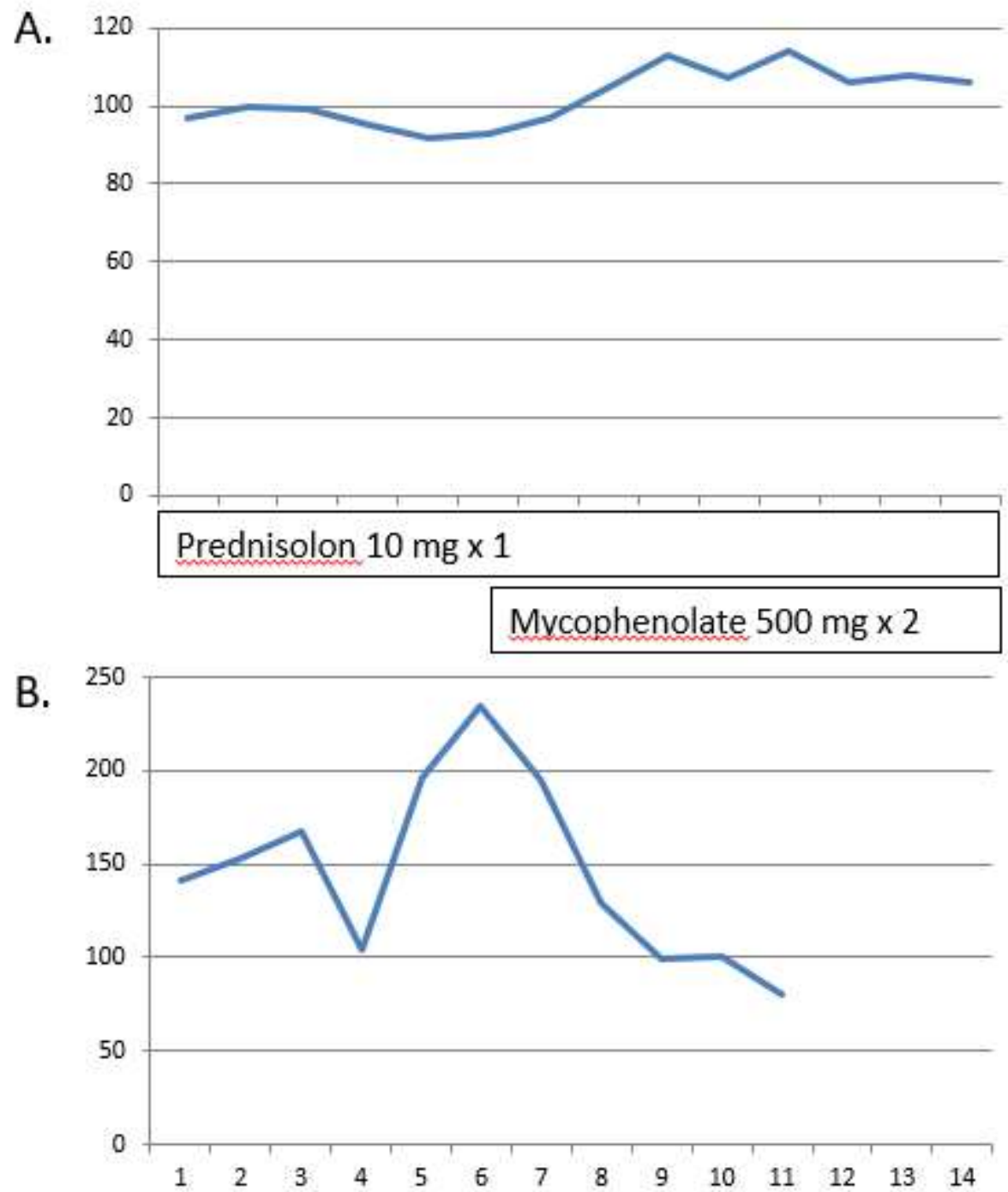
C.

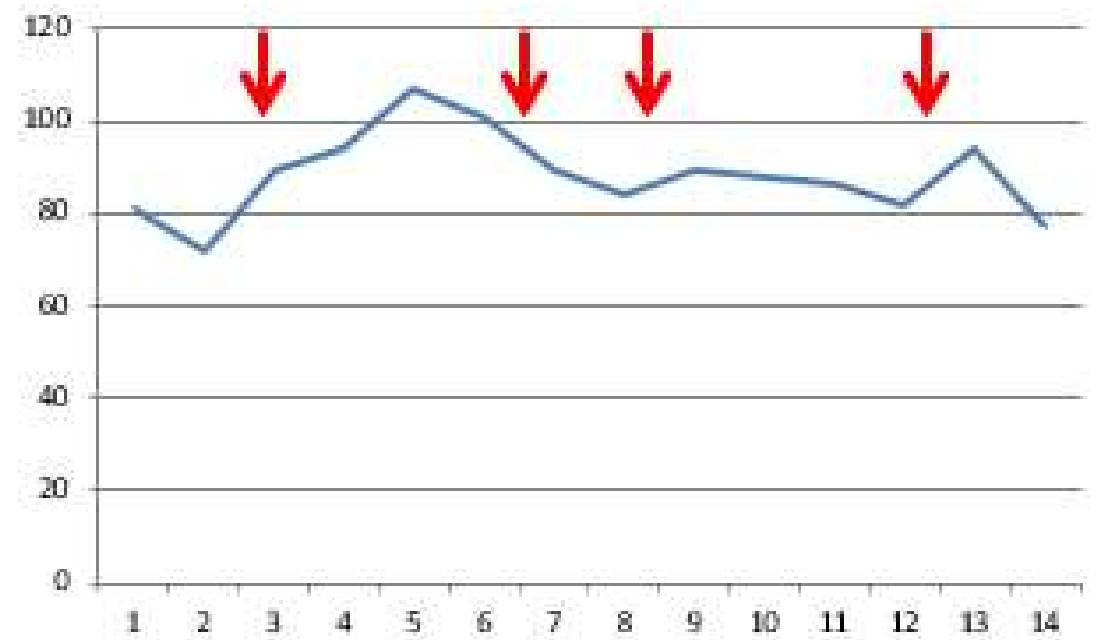

D.

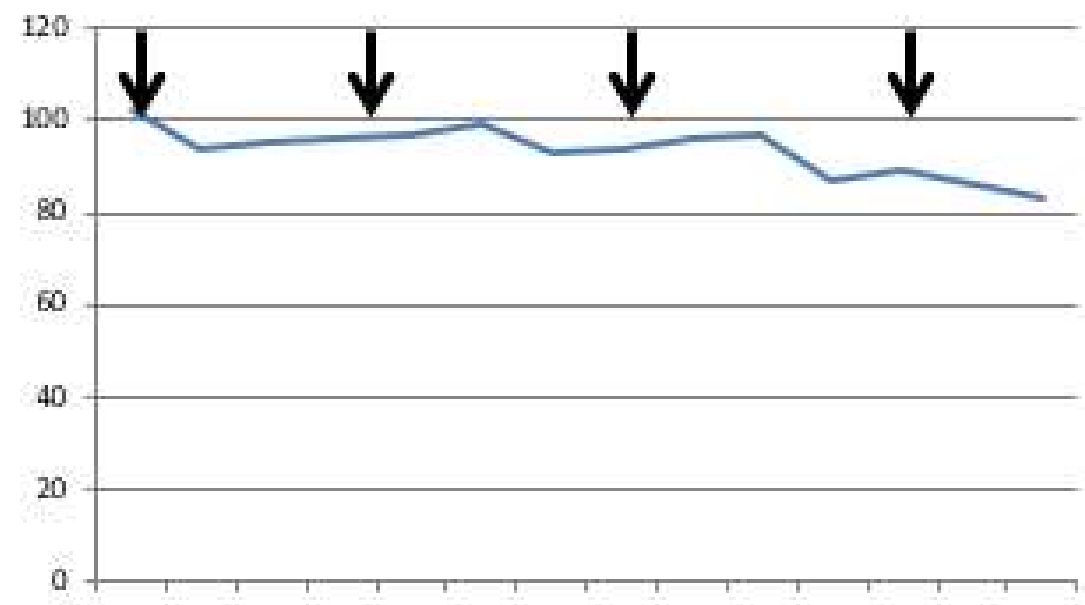

393 Patient II:4. Son of patient I:2 suffered from delayed growth and chronic rash and was diagnosed

394 with autoimmune thyroid disease with positive thyroid peroxidase antibodies at age 12 . At age 18 , he 395 developed mild anemia with blood hemoglobin 129 - $133 \mathrm{~g} / \mathrm{L}$ (normal range $134-167 \mathrm{~g} / \mathrm{L}$ ) and 396 elevated mean erythrocyte volume 98 - $104 \mathrm{fl}$ (normal range $82-98 \mathrm{fl}$ ). There was no evidence of 397 hemolysis and serum vitamin B12 concentration was normal (393 pmol/L, normal range $180-700$ $398 \mathrm{pmol} / \mathrm{L})$. He was free from any mucosal, pulmonary, joint or gastrointestinal symptoms. Although 399 ocular findings are commonly seen in HA20, his ophthalmological analysis was unremarkable. He 400 had normal absolute CD19+ B cell counts, but the percentages of his switched memory B cells were 
401 decreased and of activated B cells increased, and he did not respond normally to antipolysaccharide 402 pneumococcal antigens (Supplement Table 1).

403 Patient III:1. The 11-year-old only child of patient II:1 was born after an uncomplicated pregnancy 404 with Cesarean section after 39 weeks of gestation. At age 2.5 months, she suffered from tearfulness, 405 eating problems, puking and vomiting. Brain MRI, neurological status and thyroid hormone levels 406 were normal. Symptoms were alleviated at age 6 months by elimination diet of cow's milk. Since age 407 2, she has become tolerant to cow's milk.

408 At age $1.4 \mathrm{y}$, stunted growth, constipation, poor weight gain and appetite lead to the diagnosis of 409 autoimmune hypothyroidism with elevated thyroid stimulating hormone (TSH, $98.7 \mathrm{mU} / \mathrm{L}$, ref. 1.2 $4107.7 \mathrm{mU} / \mathrm{L}$ ), low free thyroxine $9 \mathrm{pmol} / \mathrm{L}$ (ref. $10-25 \mathrm{pmol} / \mathrm{L}$ ) and thyroid peroxidase antibody 411 positivity $(>600 \mathrm{U} / \mathrm{L}$, normal $<34 \mathrm{U} / \mathrm{L})$. Transglutaminase IgA antibodies were negative. After 412 thyroid hormone replacement, catch up growth (-2.1 to -0.9 SD) was noted but she continued to suffer 413 from constipation.

414 At age of $4 \mathrm{y}$, she complained difficulties in using a pen and her foot appeared rigid when running. 415 Occasionally, she was found to drag her leg. Stiffness in the left wrist and both ankles were found. 416 She benefitted from non-steroidal anti-inflammatory medication. At age $4.6 \mathrm{y}$, the diagnosis of 417 polyarticular juvenile idiopathic arthritis (JIA) was set by a pediatric rheumatologist, with 15 to 25 418 inflamed joints. No signs of uveitis were found. Her complete blood count was normal and anti419 nuclear antibodies, cyclic citrullinated peptide antibodies and rheumatoid factor negative. The patient 420 was negative for HLA-B27, her serum IgA was normal, C-reactive protein was $15 \mathrm{mg} / \mathrm{L}$, and 421 erythrocyte sedimentation rate only $9 \mathrm{~mm} / \mathrm{h}$.

422 She received corticosteroid injections into large joints, followed by three intravenous 423 methylprednisolone doses. The patient did not tolerate subcutaneous (s.c.) weekly methotrexate 424 (MTX) treatment. High dose (1mg/kg/week) anti-TNF monotherapy with etanercept was 425 subsequently used for 6 mo, with modest response. Anti-TNF- $\alpha$ therapy with adalimumab in 
combination with azathioprine was discontinued despite good response, because of side effects. At age $5 \mathrm{y}$, anti-IL6 therapy with tocilizumab $(10 \mathrm{mg} / \mathrm{kg}, 190 \mathrm{mg})$ once a month was started, combined with oral prednisolone $7.5 \mathrm{mg}$ every other day. Because of poor response to tocilizumab, methylprednisolone pulses $(30 \mathrm{mg} / \mathrm{kg}$ ) once a month were subsequently given. She refused to continue her oral prednisolone with a daily dose of $2.5 \mathrm{mg}$.

At age $6 \mathrm{y}$, at least 35 inflamed joints were found and the patient was referred to our tertiary hospital for intra-articular injections. White blood cell counts, immunoglobulin levels and complement activity were normal. Subcutaneous MTX (10 mg / week) and adalimumab (20mg, every 2 weeks) were started, adalimumab was later switched to intravenous infliximab (200mg, i.e. $8 \mathrm{mg} / \mathrm{kg}$ ) every 6 weeks due to challenges in subcutaneous administration. By age $7.4 \mathrm{y}$, JIA had become inactive while the patient suffered from emesis related with MTX. MTX was discontinued at age $8 \mathrm{y}$. Her joint symptoms increased 6 mo later, despite low ESR $(11 \mathrm{~mm} / \mathrm{h})$ and high levels $(405 \mathrm{AU} / \mathrm{ml})$ of antiinfliximab antibodies. With the found TNFAIP3 mutation and functional testing (Rajamäki et al), the diagnosis of HA20 was confirmed.

Based on her HA20 diagnosis, anakinra $(70 \mathrm{mg}, 2 \mathrm{mg} / \mathrm{kg})$ was tested at age $8.8 \mathrm{y}$. The patient developed painful injection site skin reactions and after two weeks her treatment was stopped by her family. Leflunomide (20 mg / every other day) in combination with golimumab (50 mg / month) and oral prednisolone were then started, with gradually decreased dose down to $2.5 \mathrm{mg}$ every other day. At age 9, the patient became asymptomatic, without inflamed joints. At age $9.3 \mathrm{y}$, her joint symptoms gradually returned, and active arthritis was found. She had developed neutralizing anti-golimumab drug antibodies with her golimumab concentrations. Her dose was increased to $100 \mathrm{mg} / \mathrm{month}$ $(2.6 \mathrm{mg} / \mathrm{kg}$ ) and azathioprine was gradually started (up to $2.2 \mathrm{mg} / \mathrm{kg} /$ day). After that, joint symptoms and drug antibodies have decreased and her polyarticular JIA has been mostly inactive. 
451 References for the supplement

452 1. Rajamäki K, Keskitalo S, Seppanen M, Kuismin O, Vahasalo P, Trotta L et al. Haploinsufficiency of A20 impairs protein-protein interactome and leads into caspase-8dependent enhancement of NLRP3 inflammasome activation. RMD.Open. 2018;4:e000740

2. Selenius JS, Martelius T, Pikkarainen S, Siitonen S, Mattila E, Pietikäinen R, et al. Unexpectedly High Prevalence of Common Variable Immunodeficiency in Finland. Front Immunol. 2017;8:1190. 